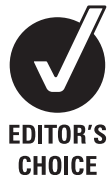

CHOICE

\title{
Growing up in a domestic violence environment: relationship with developmental trajectories of body mass index during adolescence into young adulthood
}

\author{
Hee-Jin Jun, ${ }^{1,2}$ Heather L Corliss, ${ }^{3}$ Renée Boynton-Jarrett, ${ }^{4}$ Donna Spiegelman, ${ }^{5,6}$ \\ S Bryn Austin, ${ }^{1,2,3}$ Rosalind J Wright ${ }^{1,7}$
}

${ }^{1}$ Channing Laboratory, Department of Medicine, Brigham and Women's Hospital and Harvard Medical School, Boston, Massachusetts, USA ${ }^{2}$ Department of Society, Human Development, and Health, Harvard School of Public Health, Boston, Massachusetts, USA ${ }^{3}$ Division of Adolescent/Young Adult Medicine, Children's Hospital/Harvard Medical School, Boston, Massachusetts, USA

${ }^{4}$ Division of General Pediatrics, Boston University School of Medicine/Boston Medical Center, Boston, Massachusetts, US

${ }^{5}$ Department of Epidemiology, Harvard School of Public Health, Boston, Massachusetts, USA ${ }^{6}$ Department of Biostatistics, Harvard School of Public Health, Boston, Massachusetts, USA ${ }^{7}$ Department of Environmental Health, Harvard School of Public Health, Boston, Massachusetts, USA

\section{Correspondence to}

Dr Hee-Jin Jun, Channing Laboratory, Department of Medicine, Brigham and Women's Hospital/Harvard Medical School, 181 Longwood Avenue, Boston, MA 02115, USA

nhhjj@channing.harvard.edu

Accepted 2 January 2011 Published Online First 4 February 2011

\begin{abstract}
Background This study investigated the relationship between growing up in a violent home and developmental trajectories of body mass index (BMI) in a cohort of adolescents followed longitudinally from 1996 to 2003-4.
\end{abstract}

Methods 6043 girls and 4934 boys aged 9-14 years in 1996 who reported height and weight at least two times and whose mothers completed intimate partner violence (IPV) questions at the 2001 Nurses' Health Study. Main exposure was experiencing the first family violence during early $(0-5$ years) or later $(6-11$ years) childhood, based on mother's year-specific exposure of IPV and the birth year of each participant. Mother's report of IPV was ascertained by the abuse assessment screen. Four distinct BMI trajectory groups were estimated from age-specific BMI (age 12-20 years), using general growth mixture modelling

Results Four distinct BMI trajectories were identified separately for girls and boys: healthy growth; healthy to obese; steady overweight and consistently obese. Compared with boys not exposed to violence at home, boys raised in violent homes before 5 years were at increased risk of being in the consistently obese $10 \mathrm{R}$ $=2.0 ; 95 \% \mathrm{Cl} 1.2$ to 3.5 ) and steady overweight (OR 1.4; $95 \% \mathrm{Cl} 1.1$ to 1.9 ) groups after adjusting for confounders. Girls raised in violent homes were more likely to be in the steady overweight group, but associations did not maintain statistical significance after adjusting for confounding.

Conclusion These data link children's exposure to domestic violence to a risk of unhealthy weight trajectories during adolescence in boys. Detrimental effects of exposure to a domestic violence environment may take root in the first few years of development for boys.

Domestic violence and obesity are significant global public health problems. ${ }^{1}$ Only recently has research begun to link the two together. ${ }^{2}{ }^{3}$ In the past few decades, childhood obesity has risen to epidemic proportions around the world. By 2010, more than $40 \%$ of children in north American and eastern Mediterranean WHO regions, 38\% in Europe, 27\% in the western Pacific and $22 \%$ in southeast Asia were predicted to be overweight or obese. ${ }^{4}$ In the USA, childhood obesity is rapidly increasing and is poised to overtake tobacco as the greatest contributor to preventable deaths. The prevalence of obesity among US children-now 20\%-has increased by more than $30 \%$ over the past decade. ${ }^{5}$
Among children, there is considerable variability of age of onset, developmental course and severity of overweight and obesity-characteristics that may have variable implications for future health risks. Evidence that overweight in childhood tracks into adulthood $^{6}$ and that childhood obesity is linked to adult chronic disease ${ }^{7}$ underscores the importance of better delineating growth trajectories using longitudinal data and identifying modifiable factors that contribute to such heterogeneity.

Overlapping research suggests that psychological stress plays a role in obesity. Central fat distribution is related to adverse psychological states and negative life events. ${ }^{8}$ While research has yet to elucidate fully which chronic stressors may be particularly linked to obesity, those leading to disrupted neuroendocrine mediators thought to underlie this relationship (for example, hypothalamic-pituitaryadrenal and hypothalamic-pituitary-gonadal axes) ${ }^{9}$ may be candidates worth further exploration.

Children exposed to domestic violence exhibit disrupted stress reactivity as indexed by psychological distress symptoms ${ }^{10}$ and altered sympathetic nervous system and neuroendocrine functioning. ${ }^{11}$ Moreover, research links children's exposure to domestic violence with growth deficits during pregnancy and disrupted nutritional status that may predispose to later overweight/obesity, ${ }^{2}{ }^{12}$ as well as disease correlates of obesity (eg, asthma). ${ }^{13}$ The relationship between growing up in a domestic violence household and obesity in adulthood was recently examined by Thomas et $a l^{14}$ and they found witnessing family violence in childhood (yes vs no) was positively associated with increased body mass index (BMI) at age 45 years adjusting for a number of important confounders. The relationship between witnessing domestic violence and weight trajectories over earlier periods in the life course (eg, later childhood, adolescence) has not been examined.

Family violence is the most prevalent form of violence in all counties of the world including the USA. The proportion of women reporting lifetime physical and/or sexual violence from a male partner ranged from $15 \%$ in Japan to $71 \%$ in provincial Peru. ${ }^{15}$ It has been estimated that upwards of 15 million US children are at risk of witnessing interparental violence annually. ${ }^{16}$ Growing up in a violent home has been increasingly conceptualised as a major stressor impacting children's cognitive, emotional, behavioural and social development. ${ }^{17}$ Children may be impacted through witnessing domestic violence or more indirectly through the 
effects of domestic violence on caregiving disruptions. ${ }^{18}$ Domestic violence may increase maternal stress, influence parenting behaviours, and disrupt parent-child attachment, which plays a critical role in shaping children's stress regulation systems. ${ }^{19} 20$

A developmental perspective is crucial for understanding the impact of domestic violence on paediatric health. ${ }^{17}$ Early exposure may have a greater impact given an enhanced vulnerability of underlying physiological systems to environmental influences (ie, plasticity) in younger children, ${ }^{21}$ greater dependency on their caregivers for shaping their emotional and stress-related responses ${ }^{20}$ and fewer coping abilities. ${ }^{22}$ Earlier research indicates differential influences on outcomes in preschool versus school-aged children. ${ }^{17}$ Greater vulnerability in younger children also contributes to our growing understanding of the developmental aspects of vulnerability to weight gain. ${ }^{6}$

Gender differences have been observed in adolescent $\mathrm{BMI},{ }^{23}$ and in the consequences of early life caregiving experiences and trauma exposures. ${ }^{24} 25$ Recent literature on exposure to violence and gender suggests that boys and girls may respond differently. Some evidence suggests that, in the context of exposure to domestic violence, boys exhibit more difficulties early on than girls. ${ }^{26}$ Gender differences in behavioural and psychological response may translate into variable disruption of underlying physiological stress responses (eg, hypothalamic-pituitaryadrenal axis), which may influence physical health differently in males and females. ${ }^{27}$ Notably, our group recently reported an association between chronic maternal domestic violence and obesity in 5-year-olds, with a stronger relationship seen among girls. ${ }^{2}$ Gender effects on the relationship between childhood adversities (such as family violence) and growth and obesity trajectories in later childhood and adolescence remain unstudied.

Using repeated measures of BMI from ages 12 to 20 years, this study examined whether maternal report of intimate partner violence (IPV) occurring during participants' childhood was associated with an increased risk of having an unhealthy longitudinal BMI trajectory. We examined the influence of the timing of household domestic violence exposure in preschool ( $0-5$ years) and school age (6-11 years) on adolescent BMI trajectories. We hypothesised that living in a violent household during childhood would be associated with an increased risk of manifesting an overweight or obese growth trajectory. Associations were examined in boys and girls separately.

\section{METHODS \\ Study design}

The Growing Up Today Study (GUTS) is an ongoing nationwide adolescent cohort study. Subjects are children of women participating in the Nurses' Health Study II (NHSII). In 1996, with permission of mothers, 9039 girls and 7843 boys who returned completed questionnaires were enrolled in the GUTS cohort. ${ }^{28}$ GUTS participants were mailed questionnaires annually until 2001 and biennially thereafter. In 1997, a supplemental questionnaire was mailed to participants' mothers to obtain information on early life factors ( $98 \%$ response rate).

The ongoing prospective NHSII study of registered nurses began in 1989 with 116678 women aged 25-42 years at baseline who are followed by biennial mailed questionnaires as previously detailed. ${ }^{29}$ In 2001, a supplemental questionnaire querying lifetime history of violence was mailed to 91297 NHSII participants; 68518 questionnaires were returned (75\% response rate). GUTS and NHSII study protocols were approved by the institutional review boards of Harvard School of Public Health and Brigham and Women's Hospital.

\section{Sample}

We excluded 343 GUTS participants outside the age range of 9-14 years at baseline, 3339 whose mothers did not complete the 2001 questionnaire, and 1637 without reported height and weight for at least two different ages. We also excluded 151 participants having childhood medical conditions that may interfere with growth as previously described. ${ }^{30}$ We further excluded 435 participants whose mothers reported IPV first occurring after the child was 12 years old to allow clear sequencing of exposure and outcome. The final analytical sample consisted of 10977 participants (6043 girls and 4934 boys). Gender and race/ethnicity distributions in this sample $(45 \%$ boys; $94 \%$ white) were similar to the overall GUTS baseline sample (47\% boys, 94\% white) and mean BMI (19.2 for both original and analytical samples), birth weight $(3.5 \mathrm{~kg}$ for both samples) and mean age at baseline (11.6 for original and 11.5 for analytical sample) were also very similar.

\section{Measures}

\section{Maternal experience of domestic violence}

We ascertained NHSII participants' experiences of abuse by a spouse/significant other using items from the abuse assessment screen. ${ }^{31}$ These included physical abuse (ever been hit, slapped, kicked, or otherwise physically hurt), sexual abuse (ever been forced to engage in sexual activity), and psychological abuse (ever been emotionally abused) by her spouse/significant other. Participants who endorsed abuse were asked to select the year(s) on a calendar when it occurred. Based on mother's yearspecific exposure and the birth year of each GUTS participant, the children's age-specific exposure to domestic violence was created. We categorised whether exposure first occurred during early ( $0-5$ years) or later childhood (6-11 years) given previous research indicating differential influences on outcomes in preschool versus school-aged children. ${ }^{17}$

\section{Body mass index}

GUTS participants reported their height and weight at each follow-up questionnaire, which was used to calculate their agespecific BMI $\left(\mathrm{kg} / \mathrm{m}^{2}\right)$. We excluded implausible heights, weights and BMI values based on Centers for Disease Control and Prevention criteria. ${ }^{32}$ Several groups have examined the validity of self-reported height and weight among adolescents. Correlations between measured and self-reported weight were high $(r=0.84-0.94) .{ }^{33-36}$ Two large studies showed that $94-96 \%$ of adolescents' classification of BMI status by self-reported height and weight were correct. ${ }^{33} 37$ We used actual BMI values rather than BMI z-scores as the latter are based on growth curves developed by the Centers for Disease Control and Prevention (www.cdc.gov/growthcharts). These age (month)-specific charts were created by using pooled BMI data from cross-sectional National Health and Nutrition Examination Survey data, ${ }^{38}$ which were skewed, and needed to implement slightly different normalising transformations at each month. ${ }^{39}$ Moreover, because these charts were estimated from cross-sectional data, they may not reflect typical age-related patterns of BMI change among children. Given this, the use of an actual BMI value is desirable to assess longitudinal trends of BMI for adolescents and it also enhances interpretability. ${ }^{39}$

\section{Demographic, behavioural and familial characteristics}

On the basis of theoretical relevance and empirical evidence from the literature, a number of potential confounders were identified: baseline age, birth weight, ${ }^{40}$ race/ethnicity, ${ }^{41}$ socioeconomic status (SES) as indexed by household parental 
income, ${ }^{42}$ and mother's pre-pregnancy BMI. ${ }^{43}$ Given observed gender differences in both adolescent $\mathrm{BMI},{ }^{23}$ and in the consequences of child abuse, ${ }^{44}$ all the analyses were gender stratified.

\section{Statistical analyses}

Latent class BMI trajectories were estimated using general growth mixture modelling (GMM) in Mplus version $4 .{ }^{45}$ The repeated outcome measure was continuous BMI at ages $12-20$ years. GMM is a latent growth modelling technique that empirically classifies heterogeneity in developmental trajectories into groups that share similar growth patterns. ${ }^{45} \mathrm{GMM}$ assumes that individuals belong to two or more distinct subpopulations with different developmental trajectories. ${ }^{45}$ We included age at baseline in the GMM equations that estimated the intercept and slope growth factors and the BMI trajectory latent classes because the youth in our study were different ages at the beginning of assessment (9-14 years) and it is possible that there could be age cohort differences in BMI on account of the fact that BMI has been increasing over time in the adolescent population. If there are important age cohort differences in BMI, then including age in the growth mixture models would result in a more accurate estimation of class membership. Figure 1 is a graphic depiction of the model specified for analysis.

We used maximum likelihood estimation using the expectation-maximisation algorithm. Missing data were handled applying the assumption of missing at random. ${ }^{46}$ Bayesian information criterion (BIC), ${ }^{47}$ probability of correct model ${ }^{48}$ and the Lo-Mendell-Rubin likelihood tatio test (LMR LRT) ${ }^{49}$ were used to select the optimal number of trajectory groups. Children were assigned to the trajectory group for which they had the highest posterior probability of membership. ${ }^{48}$ Entropy, a weighted average of posterior probability, was used to assess classification quality, a value close to one indicates clear delineation of classes.

We regressed trajectory group membership on domestic violence exposure using multinomial logistic regression in SAS version 9.1 adjusting for potential confounder variables: race/ ethnicity, baseline age (model 1), plus birth weight, maternal pre-pregnancy BMI (model 2), and finally adding household parental income (model 3).

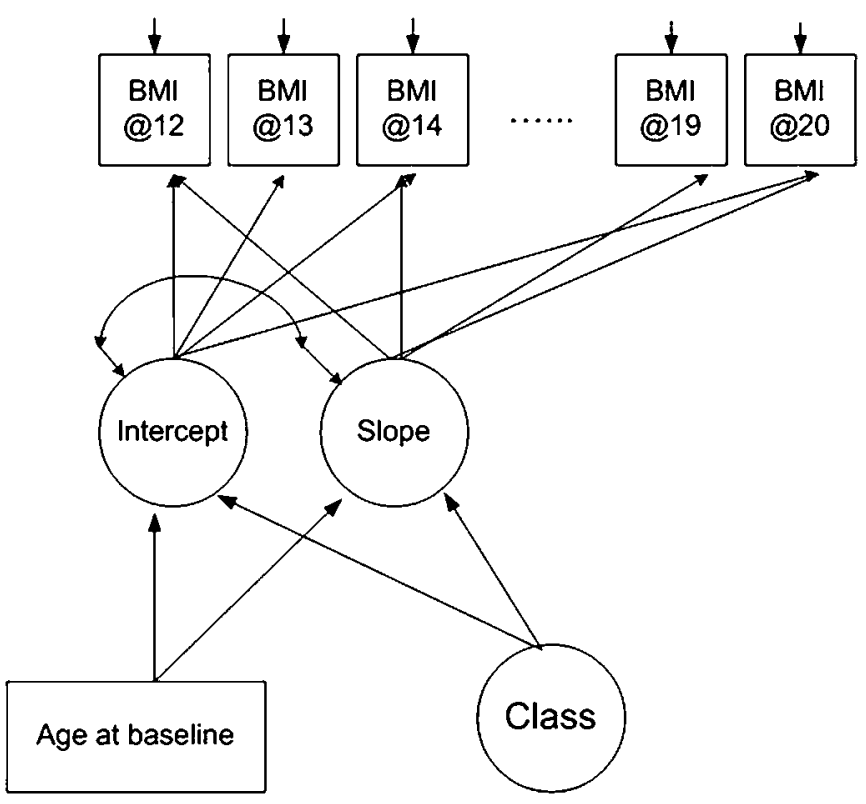

Figure 1 General growth mixture model. BMI, body mass index.
Table 1 Indices of goodness of fit of growth mixture model

\begin{tabular}{lllllllr}
\hline $\begin{array}{l}\text { No of latent } \\
\text { classes }\end{array}$ & AIC & $\begin{array}{l}\text { Sample-size } \\
\text { adjusted BIC }\end{array}$ & Entropy & Value & (df) & p Value \\
\hline Boys & & & & & & & \\
1 & 99373 & 99426 & & & & \\
2 & 98176 & 98240 & 0.910 & 1157.70 & $(3)$ & $<0.0001$ \\
3 & 97741 & 97815 & 0.906 & 423.70 & $(3)$ & 0.0017 \\
4 & 97442 & 97526 & 0.896 & 294.01 & $(3)$ & 0.0002 \\
5 & 97296 & 97390 & 0.898 & 146.31 & $(3)$ & 0.0551 \\
Girls & & & & & & \\
1 & 128401 & 128458 & & & & \\
2 & 126599 & 126666 & 0.951 & 1741.77 & $(3)$ & $<0.0001$ \\
3 & 126092 & 126170 & 0.931 & 493.99 & $(3)$ & 0.0002 \\
4 & 125681 & 125770 & 0.926 & 401.18 & $(3)$ & 0.0191 \\
5 & 125460 & 125560 & 0.932 & 219.29 & $(3)$ & 0.0234 \\
\hline
\end{tabular}

AIC, Akaike information criterion; BIC, Bayesian information criterion; LMR LRT, Lo-Mendell-Rubin likelihood ratio test.

\section{RESULTS}

\section{Gender-specific BMI trajectories}

Beginning with a single trajectory model, we compared five models to determine the optimal number of groups explaining the BMI growth trajectories. Model fit statistics are presented in table 1 . For boys, the BIC value decreased with each increase in the number of classes. However, the LMR LRT estimate was not significant for the five-trajectory model $(p=0.06)$, suggesting the four-trajectory model was the best fit (figure 2A). For girls, the

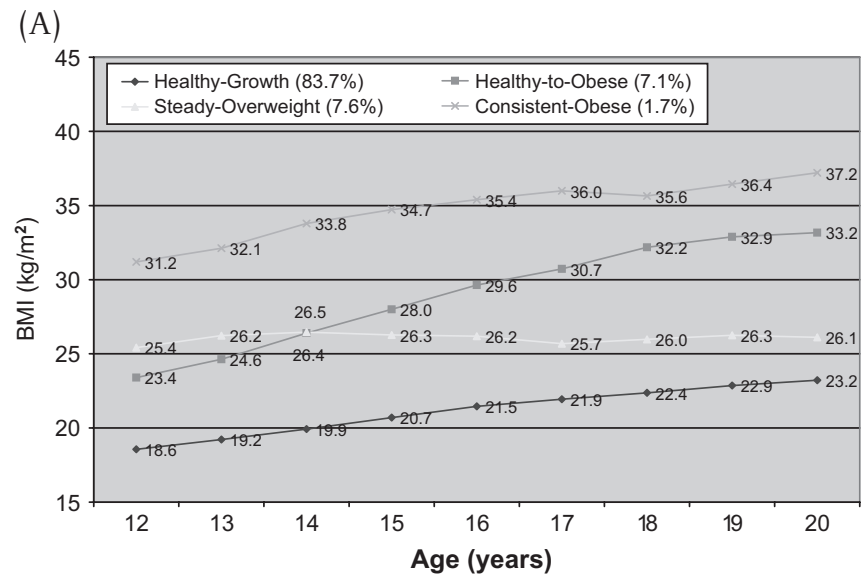

(B)

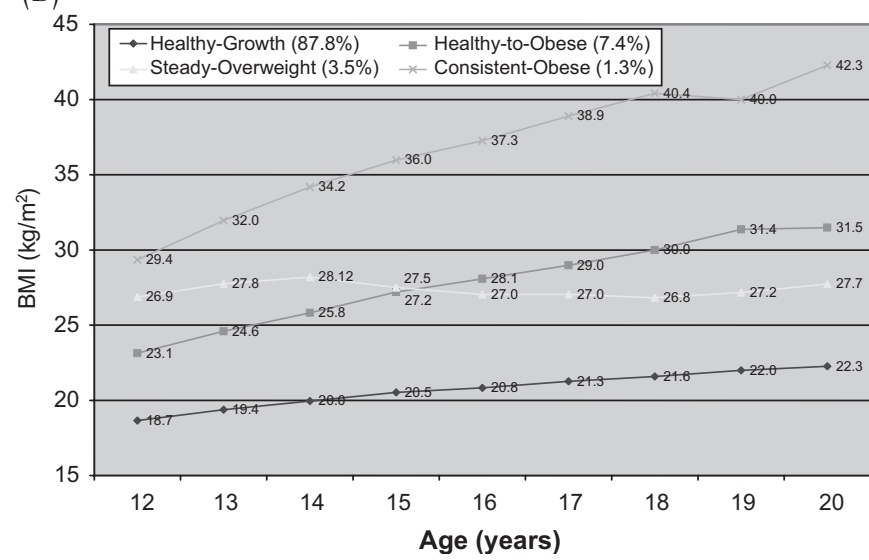

Figure 2 (A) Body mass index (BMI) trajectories among boys (Growing Up Today Study (GUTS) cohort, $N=5124)$. (B) BMI trajectories among girls (GUTS cohort, $\mathrm{N}=6288$ ). 
BIC value continually decreased from the single to the fivetrajectory model, and the LMR LRT estimate was significant for the five-trajectory model $(p=0.02)$. However, in the fivetrajectory model, one group had only 65 participants, limiting our ability to make inferences about risk factors for this group. Therefore, we specified a model with four groups similar to boys (figure 2B).

Table 2 summarises the distributions of maternal domestic violence and other covariates for the analytical sample and across genders.

\section{Boys}

Most boys were in the healthy BMI range for the study period (healthy growth group, $83.7 \%$ ). The healthy to obese trajectory included $7.1 \%$ who started off in the healthy BMI range but became obese over time. The steady overweight group included $7.6 \%$ of boys. The fourth trajectory, consistently obese $(1.7 \%)$, included those who were obese across the study period.

\section{Girls}

The girls' BMI trajectories were qualitatively similar to boys', with $87.8 \%$ in the healthy growth group, $7.4 \%$ in the healthy obese group, $3.5 \%$ in the steady overweight group and $1.3 \%$ in the consistently obese group.

\section{Associations of a domestic violence environment with BMI trajectories \\ Boys}

We fit multinomial logistic regression models to determine whether growing up in a domestic violence household was associated with BMI trajectory group membership (table 3). In model 1 , boys living in a domestic violence household from ages

Table 2 Sample characteristics of children and their mothers by gender. GUTS cohort (1996-2003), USA

\begin{tabular}{|c|c|c|}
\hline & $\begin{array}{l}\text { Boys } \\
N(\%) \\
4934(100.0)\end{array}$ & $\begin{array}{l}\text { Girls } \\
\text { N (\%) } \\
6043(100.0\end{array}$ \\
\hline \multicolumn{3}{|c|}{ Age at onset of domestic violence, years } \\
\hline None & $3756(76.1)$ & $4552(75.3)$ \\
\hline $0-5$ & $901(18.3)$ & $1142(18.9)$ \\
\hline $6-11$ & $277(5.6)$ & $349(5.8)$ \\
\hline \multicolumn{3}{|l|}{ Race/ethnicity } \\
\hline White & $4609(93.4)$ & $5657(93.6)$ \\
\hline All others & $325(6.6)$ & $386(6.4)$ \\
\hline \multicolumn{3}{|l|}{ Age at baseline, years } \\
\hline $9-11$ & $2542(51.5)$ & $3001(49.7)$ \\
\hline $12-14$ & $2392(48.5)$ & $3042(50.3)$ \\
\hline \multicolumn{3}{|l|}{ Birth weight, $\mathrm{kg}$} \\
\hline Less than 2.5 & $175(3.5)$ & $242(4.0)$ \\
\hline 2.5 to 3.0 & $428(8.7)$ & $741(12.3)$ \\
\hline 3.0 to 3.5 & $1507(30.5)$ & $2343(38.8)$ \\
\hline 3.5 to 4.0 & $1835(37.2)$ & $1962(32.5)$ \\
\hline 4.0 to 4.5 & $760(15.4)$ & $581(9.6)$ \\
\hline More than 4.5 & $179(3.6)$ & $102(1.7)$ \\
\hline \multicolumn{3}{|l|}{ Maternal BMI before pregnancy } \\
\hline Under weight $(<18.5)$ & $270(5.5)$ & $318(5.3)$ \\
\hline Normal weight (18.5-24.9) & $3496(70.9)$ & $4168(69.0)$ \\
\hline Overweight (25.0-29.9) & $473(9.6)$ & $607(10.0)$ \\
\hline Obese $(\geq 30.0)$ & $158(3.2)$ & $203(3.4)$ \\
\hline \multicolumn{3}{|l|}{ Household parental income, US\$ } \\
\hline$\geq 50000$ & $3719(75.4)$ & $4491(74.3)$ \\
\hline$<50000$ & $529(10.7)$ & $663(11.0)$ \\
\hline Missing information & $686(13.9)$ & $889(14.7)$ \\
\hline
\end{tabular}

BMI, body mass index; GUTS, Growing Up Today Study.
$0-5$ years were more likely to be in the consistent obese group and the steady overweight group; boys exposed to violence from 6 to 11 years were also more likely to be in the consistently obese group. Further adjustment for covariates did not substantially change the estimates.

\section{Girls}

In age and race/ethnicity adjusted models, compared with the healthy growth referent group, girls showed an elevated risk of being in the steady overweight group if they experienced household domestic violence from ages 0 to 5 years and of being in the persistently obese group when domestic violence occurred between ages 6 and 11 years, albeit the latter effect did not reach statistical significance (model 1 , table 3 ). The effect of domestic violence in early childhood $(0-5$ years) on being steady overweight among the girls remained when further adjusting for birth weight and maternal pre-pregnancy BMI but was no longer significant when further adjusted for parental household income.

\section{DISCUSSION}

This study found that, for boys, living in domestic violence households in the early childhood period was associated with the development and maintenance of obesity, and living in a domestic violence household in later childhood was associated with being persistently obese. Among girls, early experiences of domestic violence were associated with an increased likelihood of being in the steady overweight group even after adjusting for race/ethnicity, baseline age, maternal pre-pregnancy BMI and child's birth weight. This association was no longer significant when adjusting further for household parental income (ie, SES). While there was a suggestion among girls that late childhood domestic violence was related to being in the consistently obese group, this did not reach statistical significance.

These analyses add to the literature in three important ways. First, given the emerging recognition that weight trajectories tracking from early to later life may differentially influence health, we characterised BMI trajectories during adolescence in a large adolescent cohort. Second, we present prospective results demonstrating that children growing up in a domestic violence environment may be at increased risk of manifesting high-risk BMI growth trajectories compared with their counterparts who were not exposed to domestic violence. Finally, notable gender differences emerged in that boys' BMI development appeared to be more strongly impacted by exposure to a domestic violence environment than girls'.

The growth trajectories identified in GUTS are comparable to those seen in another study examining childhood trajectories of obesity. Mustillo et al ${ }^{50}$ identified four obesity trajectories within a predominantly rural population of white non-Hispanic children between 9 and 16 years that were remarkably similar to ours: never obese-children who were never or rarely obese; adolescent obese-children who started off in the normal weight range during childhood but became obese over time; chronically obese-children who were obese for most or all waves of observation; and childhood obese - those who were obese during late childhood and whose weight fell during adolescence.

Studies examining relationships of other types of violence to obesity may provide a helpful context for interpreting this study's findings and noted differences based on gender. Studies suggest that childhood abuse is associated with obesity in young adulthood. ${ }^{51-53}$ Lissau and Sorenson ${ }^{51}$ linked parental neglect during childhood with an increased risk of obesity in young adulthood. This is notable given other evidence showing that 
Table 3 OR and 95\% Cl for child's age at mother's first report of domestic violence predicting healthy growth versus other types of growth trajectory classes

\begin{tabular}{|c|c|c|c|c|c|c|}
\hline \multicolumn{7}{|l|}{ Boys } \\
\hline & \multicolumn{2}{|l|}{ Model 1} & \multicolumn{2}{|l|}{ Model 2} & \multicolumn{2}{|l|}{ Model 3} \\
\hline \multicolumn{7}{|l|}{ Healthy to obese } \\
\hline No maternal report of DV & 1.0 & & 1.0 & & 1.0 & \\
\hline First maternal report of DV b/w $0-5$ years & $1.0(0.7$ to 1.3$)$ & 0.796 & $1.0(0.7$ to 1.3$)$ & 0.860 & $1.0(0.7$ to 1.3$)$ & 0.781 \\
\hline First maternal report of DV b/w $6-11$ years & $0.6(0.3$ to 1.1$)$ & 0.127 & $0.6(0.3$ to 1.1$)$ & 0.108 & $0.6(0.3$ to 1.1$)$ & 0.099 \\
\hline \multicolumn{7}{|l|}{ Steady overweight } \\
\hline No maternal report of DV & 1.0 & 1.0 & & & 1.0 & \\
\hline First maternal report of DV b/w $0-5$ years & $1.5(1.1$ to 1.9$)$ & 0.006 & 1.5 (1.1 to 1.9$)$ & 0.004 & $1.5(1.1$ to 1.9$)$ & 0.006 \\
\hline First maternal report of DV b/w 6-11 years & $0.9(0.5$ to 1.5$)$ & 0.732 & $0.9(0.5$ to 1.5$)$ & 0.679 & $0.9(0.5$ to 1.5$)$ & 0.657 \\
\hline \multicolumn{7}{|l|}{ Consistently obese } \\
\hline No maternal report of DV & 1.0 & 1.0 & & & 1.0 & \\
\hline First maternal report of DV b/w $0-5$ years & $2.0(1.2$ to 3.4$)$ & 0.013 & $2.0(1.2$ to 3.5$)$ & 0.012 & $1.9(1.1$ to 3.4$)$ & 0.019 \\
\hline First maternal report of DV b/w 6-11 years & $3.0(1.5$ to 6.1$)$ & 0.002 & $3.0(1.4$ to 6.1$)$ & 0.003 & $2.8(1.4$ to 5.9$)$ & 0.005 \\
\hline \multicolumn{7}{|l|}{ Girls } \\
\hline & Model 1 & & Model 2 & & Model 3 & \\
\hline \multicolumn{7}{|l|}{ Healthy to obese } \\
\hline No maternal report of DV & 1.0 & & 1.0 & & 1.0 & \\
\hline First maternal report of DV b/w $0-5$ years & $1.2(0.9$ to 1.5$)$ & 0.236 & $1.1(0.9$ to 1.5$)$ & 0.356 & $1.1(0.9$ to 1.4$)$ & 0.411 \\
\hline First maternal report of DV b/w 6-11 years & $0.9(0.5$ to 1.4$)$ & 0.548 & $0.9(0.5$ to 1.4$)$ & 0.519 & $0.8(0.5$ to 1.4$)$ & 0.499 \\
\hline \multicolumn{7}{|l|}{ Steady overweight } \\
\hline No maternal report of DV & 1.0 & & 1.0 & & 1.0 & \\
\hline First maternal report of DV b/w $0-5$ years & $1.5(1.0$ to 2.1$)$ & 0.026 & $1.4(1.0$ to 2.0$)$ & 0.040 & $1.3(0.9$ to 1.8$)$ & 0.189 \\
\hline First maternal report of DV b/w 6-11 years & $1.1(0.6$ to 2.1$)$ & 0.735 & $1.1(0.6$ to 2.1$)$ & 0.733 & $1.0(0.5$ to 1.9$)$ & 0.918 \\
\hline \multicolumn{7}{|l|}{ Consistently obese } \\
\hline No maternal report of DV & 1.0 & & 1.0 & & 1.0 & \\
\hline First maternal report of DV b/w $0-5$ years & $1.0(0.5$ to 1.9$)$ & 0.978 & $1.0(0.5$ to 1.9$)$ & 0.982 & $0.9(0.5$ to 1.7$)$ & 0.773 \\
\hline First maternal report of DV b/w $6-11$ years & $1.7(0.8$ to 3.8$)$ & 0.179 & $1.9(0.8$ to 4.2$)$ & 0.135 & $1.7(0.8$ to 4.0$)$ & 0.191 \\
\hline Adjusted for & icity and age at & & & & & \\
\hline Adjusted for & es in model 1 plu & al pre-pr & BMI and birth we & & & \\
\hline Adjusted for & es in model 2 plu & old pare & me at 2001 from & 1999 & & \\
\hline
\end{tabular}

$\mathrm{BMI}$, body mass index; DV, domestic violence.

domestic violence can disrupt parenting behaviours and decrease maternal sensitivity and attentiveness. ${ }^{18} 54$ Using data from the National Longitudinal Study of Adolescent Health, Hussey et $a l^{52}$ found a $20 \%$ increased risk of overweight in young adulthood among those physically assaulted before the 6th grade. In a prospective study of 84 women who were sexually abused during childhood and 89 demographically similar but non-abused women, Noll et al ${ }^{53}$ tracked BMI during childhood and adolescence and found abused women did not differ from their non-abused counterparts. However, they found that by young adulthood, women exposed to sexual abuse had a steeper rate of increase in BMI and they were significantly more likely to be obese (42.3\%) than were the non-abused women (28.4\%) as young adults. Notably, our study did not observe a significant relationship between earlier domestic violence exposure and unhealthy BMI trajectories among girls in fully adjusted models. Perhaps there is a lag effect that will become evident when these women are followed longer. Noll and colleagues ${ }^{53}$ did not study boys so we do not know whether differences in lag effects may explain the gender differences observed in this study.

Other factors may help explain differential gender effects. Overlapping research demonstrates gender differences in children's response to general stress throughout development. ${ }^{55}$ Moreover, children's appraisals and strategies for coping with interparental conflict differ among boys and girls, which then mediate adjustment ${ }^{26}$ albeit this remains understudied. ${ }^{17}$ Early life caregiving experiences and trauma exposures have been shown to influence childhood emotional understanding and expression, with some studies showing differential gender effects. $^{24}$ Children exposed to violence and neglect in their environment may express more negative emotion and adverse stress reactivity. Notably, a recent study in older adult men and women found a relationship between negative affect and BMI trajectories only among men. ${ }^{14}$ It is also notable that among girls, early childhood experiences of domestic violence were significantly associated with an increased risk of being in the steady overweight group (similar to boys) until analyses were adjusted for SES in the home. This may suggest that girls compared with boys are more vulnerable to other childhood adversities that may co-vary with SES not measured in this study. We know that children who experience family violence during childhood tend to experience other adversities that may also be linked to later obesity (eg, poor nutrition, poverty, other stressors) ${ }^{14} 53$ or have synergistic effects. ${ }^{56}$ This should be considered in future studies.

In our study, we used GMM to identify four distinct subgroups of adolescents who differed in their development of BMI from ages 12 to 20 years. The sample used for these analyses has three advantages: a large enough sample size to conduct gender-specific analyses; repeated measurements of BMI; and measurement of a wide range of risk factors and correlates of domestic violence.

In interpreting our results, some limitations should also be considered. First, height and weight were self-reported in this study as direct measurement of anthropometry were not feasible given that participants are spread out across the USA. As noted 
previously, studies have shown that self-report in adolescents is a reasonable surrogate and valid alternative. ${ }^{33-35}$ In particular, data show that categorisation into BMI categories based on self-report data is highly reliable.

Second, the measure of family violence used in this analysis, the AAS, was designed as a brief clinical screening instrument and may not be as sensitive as other multi-item measures of family violence exposure. For example, studies have found that the physical abuse item on the AAS is less sensitive than the composite of items from the conflict tactics scale 2 (CTS2), ${ }^{57} 58$ especially in relation to identifying those experiencing minor abuse, and this may result in false-negative cases. ${ }^{58}$ However, such underreporting would bias effects towards the null and yet associations were evident. Notably, the AAS also assesses emotional and sexual abuses, which were also prevalent in our sample. Measuring emotional and sexual abuse in addition to physical abuse may minimise the misclassification of those exposed to domestic violence when using the AAS. Nonetheless, future work in this area would be strengthened by using validated multi-item surveys that more comprehensively assess co-occurring types of violence (eg, physical, sexual, emotional abuse) to enhance precision of the measurement as well as allowing the examination of salient characteristics (eg, severity, frequency of exposure).

Third, this study relied on mothers' retrospective self-report of abuse. Therefore, we do not know the extent to which maternal report of her own experience represents the child's experiences. Conversely, because children may be less likely to recall events occurring during early childhood, ${ }^{59}$ maternal report may be a better way to measure early exposures. Notably, the independent and dependent variables were not reported at the same time and were not ascertained from the same individuals; therefore the report of BMI is independent of the report of mother's experience of IPV. Children who witness domestic violence may also be more likely to experience direct abuse. Future research assessing multiple forms of violence exposure including

\section{What is already known on this subject}

Although childhood obesity is a growing problem, few studies have traced developmental trajectories of BMI during adolescence and even fewer studies have examined the factors contributing to differences in adolescent BMI trajectories that may be amenable to prevention or intervention.

\section{What this study adds}

- Four distinct growth trajectories were identified among these adolescent boys and girls: healthy growth, healthy to obese, steady overweight and consistently obese.

- Growing up in a domestic violence household from birth to the age of 5 years was associated with being in an unhealthy weight trajectory group in adolescent boys.

- Detrimental effects of growing up in a domestic violence environment may take root in the first few years of development.

- Identifying and responding to mothers experiencing domestic violence during these early years may be a way to reduce later health consequences in their children. witnessing and direct victimisation and their influences on mediating processes (eg, parenting, attachment) is needed to understand these relationships more fully.

In summary, these data link children's exposure to domestic violence to unhealthy weight trajectories. There are biologically plausible mechanisms through which chronic stressors such as childhood exposure to domestic violence may lead to unhealthy weight gain. In response to stress, children may increase food intake ${ }^{60}$ and/or decrease activity. ${ }^{61}$ Alternatively, disruption in the children's neuroendocrine system may result in altered metabolism, activity levels, or appetite. ${ }^{9}{ }^{6}$ Further research is needed to examine these potential mechanisms. Our findings also suggest that detrimental effects may take root in the first few years of development. To identify and respond to mothers experiencing domestic violence during these early years may be a way to reduce later health consequences in their children. ${ }^{63}$ The response should include identifying ways to provide a safe home environment for both the child and the abused caregiver.

Acknowledgements The authors would like to thank the nurses and their children across the country who participated in the Nurses' Health Study II and the Growing Up Today Study.

Funding This study was funded by NIH grants HD049889 and HL064108. During preparation of this manuscript RBJ was supported by the William T Grant Foundation.

\section{Competing interests None.}

Patient consent Obtained

Ethics approval This study was conducted with the approval of the Brigham and Women's Hospital and Harvard School of Public Health.

Provenance and peer review Not commissioned; externally peer reviewed.

\section{REFERENCES}

1. Ellsberg M, Jansen HA, Heise L, et al. Intimate partner violence and women's physical and mental health in the WHO multi-country study on women's health and domestic violence: an observational study. Lancet 2008;371:1165-72.

2. Boynton-Jarrett R, Fargnoli J, Suglia SF, et al. Association between maternal intimate partner violence and incident obesity in preschool-aged children: results from the Fragile Families and Child Well-being Study. Arch Pediatr Adolesc Med 2010;164:540-6.

3. Yount K, Li L. Domestic violence and obesity in Egyptian women. J Biosoc Sci 2010;1:1-15.

4. Han JC, Lawlor DA, Kimm SY. Childhood obesity. Lancet 2010;375:1737-48.

5. Dietz WH. Overweight in childhood and adolescence. New Eng/ J Med 2004;350:855-7.

6. Adair LS. Child and adolescent obesity: epidemiology and developmental perspectives. Physiol Behav 2008;94:8-16.

7. Bellin L, Huang R-C. Childhood obesity, hypertension, the metabolic syndrome and adult cardiovascular disease. Clin Exp Pharmacol Physiol 2008;35:409-11.

8. Lloyd C, Wing RR, Orchard TJ. Waist to hip ratio and psychosocial factors in adults with insulin-dependent diabetes mellitus: the Pittsburgh Epidemiology of Diabetes Complications Study. Metabolism 1996;45:268-72.

9. Bjorntorp P. Do stress reactions cause abdominal obesity and comorbidities? Obes Rev 2001;2:73-86.

10. Bogat GA, DeJonghe $E$, Levendosky $A A$, et al. Trauma symptoms among infants exposed to intimate partner violence. Child Abuse Neglect 2006;30:109-25.

11. Saltzman KM, Holden GW, Holahan CJ. The psychobiology of children exposed to marital violence. J Clin Child Adolesc 2005;34:129-39.

12. Hasselmann $\mathbf{M H}$, Reichenheim ME. Parental violence and the occurrence of severe and acute malnutrition in childhood. Paediatr Perinat Epidemiol 2006;20:299-311.

13. Suglia SF, Enlow MB, Kullowatz A, et al. Maternal intimate partner violence and increased asthma incidence in children: buffering effects of supportive caregiving. Arch Pediat Adolesc Med 2009;163:244-50.

14. Thomas C, Hypponen E, Power C. Obesity and type 2 diabetes risk in midadult life: the role of childhood adversity. Pediatrics 2008;121:e1240-9.

15. García-Moreno C, Jansen HAFM, Ellsberg M, et al. WHO Multi-country Study on Women's Health and Domestic Violence Against Women. http://www.who.int/ gender/violence/who_multicountry_study/en/ (accessed 10 Oct 2010).

16. McDonald R, Jouriles EN, Briggs-Gowan MJ, et al. Violence toward a family member, angry adult conflict, and child adjustment difficulties: relations in families with 1- to 3-year-old children. J Fam Psychol 2007;21:176-84.

17. Holt S, Buckley $\mathrm{H}$, Whelan $\mathrm{S}$. The impact of exposure to domestic violence on children and young people: a review of the literature. Child Abuse Neglect 2008;32:797-810. 
18. Osofsky JD. Children who witness domestic violence: the invisible victims. Social Policy Report 1995;9:1-16.

19. Belsky J. The determinants of parenting: a process model. Child Dev 1984;55:83-96.

20. Sroufe L, Egeland B, Carlson E, et al. Placing early attachment experiences in developmental context: the Minnesota Longitudinal Study. In: Grossmann K, Grossmann K, Waters E, eds. Attachment from infancy to adulthood: the major longitudinal studies. New York, USA: Guilford Publications, 2005:48-70.

21. Gunnar MR, Fisher PA. The Early Experience Stress and Prevention Network. Bringing basic research on early experience and stress neurobiology to bear on preventive interventions for neglected and maltreated children. Dev Psychopathol 2006;18:651-77.

22. Liebermann D, Giesbrecht G, Muller U. Cognitive and emotional aspects of self-regulation in preschoolers. Cognitive Dev 2007;22:511.

23. Shaw N, Crabtree N, Kibirige $\mathrm{M}$, et al. Ethnic and gender differences in body fat in British schoolchildren as measured by DXA. ArchDis Child 2007;92:872-5.

24. Chaplin TM, Cole PM, Zahn-Waxler C. Parental socialization of emotion expression: gender differences and relations to child adjustment. Emotion 2005:5:80-8.

25. Edwards A, Shipman K, Brown A. The socialization of emotional understanding: a comparison of neglectful and nonneglectful mothers and their children. Child Maltreatm 2005:10:293-304.

26. Kerig P, Fedorowicz A, Brown C, et al. When warriors are worriers: gender and children's coping with interparental violence. J Emot Abuse 1999;1:89-114.

27. Brummett B, Muller C, Collins A, et al. 5-HTTLPR and gender moderate changes in negative affect responses to tryptophan infusion. Behav Genet 2008;38: 476-83.

28. The Growing Up Today Study. GUTS: modern lifestyle, future health. http://www. nhs2.org/gutsblog/cmsmadesimple/index.php?page=about (accessed 3 Dec 2009)

29. The Nurses Health Study. The Nurses Health Study. http://www.channing.harvard edu/nhs/history/index.shtml\#histll (accessed 3 Dec 2009).

30. Gillman MW, Rifas-Shiman SL, Berkey CS, et al. Breast-feeding and overweight in adolescence. Epidemiology 2006;17:112-14.

31. McFarlane J, Parker B, Soeken K, et al. Assessing for abuse during pregnancy. Severity and frequency of injuries and associated entry into prenatal care. JAMA 1992;267:3176-8.

32. Centers for Disease Control and Prevention. SAS program for the CDC growth charts. http://www.cdc.gov/nchs/about/major/nhanes/growthcharts/datafiles.htm (accessed 1 Feb 2009)

33. Shannon B, Smiciklas-Wright H, Wang MO. Inaccuracies in self-reported weights and heights of a sample of sixth-grade children. J Am Diet Assoc 1991;91:675-8

34. Strauss RS, Knight J. Influence of the home environment on the development of obesity in children. Pediatrics 1999;103:e85.

35. Goodman E, Hinden BR, Khandelwal S. Accuracy of teen and parental reports of obesity and body mass index. Pediatrics 2000;106:52-8

36. Field $\mathbf{A E}$, Aneja P, Rosner B. The validity of self-reported weight change among adolescents and young adults. Obesity 2007;15:2357-64.

37. Rockett HR, Wolf AM, Colditz GA. Development and reproducibility of a food frequency questionnaire to assess diets of older children and adolescents. J Am Diet Assoc 1995;95:336-40.

38. Ogden CL, Kuczmarski RJ, Flegal KM, et al. Centers for Disease Control and Prevention 2000 growth charts for the United States: improvements to the 1977 National Center for Health Statistics version. Pediatrics 2002;109:45-60.

39. Berkey CS, Colditz GA. Adiposity in adolescents: change in actual BMI works better than change in BMl z score for longitudinal studies. Ann Epidemiol 2007;17:44-50.

40. Parsons TJ, Power C, Logan S, et al. Childhood predictors of adult obesity: a systematic review. Int J Obes Relat Metab Disord 1999;23(Suppl 8):S1-107.
41. White MA, O'Neil PM, Kolotkin RL, et al. Gender, race, and obesity-related quality of life at extreme levels of obesity. Obes Res 2004;12:949-55.

42. Strauss RS. Comparison of measured and self-reported weight and height in a cross-sectional sample of young adolescents. Int J Obes Relat Metab Disord 1999:23:904-8.

43. Epstein LH, Wu YW, Paluch RA, et al. Asthma and maternal body mass index are related to pediatric body mass index and obesity: results from the Third National Health and Nutrition Examination Survey. Obes Res 2000;8:575-81.

44. Thompson MP, Kingree JB, Desai S. Gender differences in long-term health consequences of physical abuse of children: data from a nationally representative survey. Am J Public Health 2004;94:599-604.

45. Muthen B. Latent variable analysis: growth mixture modeling and related techniques for longitudinal data. In: Kaplan D, ed. Handbook of quantitative methodology for the social sciences. Newbury Park, CA: Sage Publications, 2004

46. Little R, Rubin D. Statistical analysis with missing data. New York, NY: John Wiley and Sons, 2002.

47. Schwarz G. Estimating the dimension of a model. Ann Stat 1978:6:461-4.

48. Nagin D, Tremblay R. Analyzing developmental trajectories of distinct but related behaviors: a group-based method. Psychol Methods 2001;6:18-34

49. Lo Y, Mendell N, Rubin D. Testing the number of components in a normal mixture. Biometrika 2001;88:767-78.

50. Mustillo S, Worthman C, Erkanli A, et al. Obesity and psychiatric disorder: developmental trajectories. Pediatrics 2003;111:851-9.

51. Lissau I, Sorensen TI. Parental neglect during childhood and increased risk of obesity in young adulthood. Lancet 1994;343:324-7.

52. Hussey JM, Chang JJ, Kotch JB. Child maltreatment in the United States: prevalence, risk factors, and adolescent health consequences. Pediatrics 2006;118:933-42.

53. Noll JG, Zeller MH, Trickett PK, et al. Obesity risk for female victims of childhood sexual abuse: a prospective study. Pediatrics 2007;120:e61-7.

54. Van Horn P, Lieberman A. Domestic violence and parenting: a review of the literature. San Francisco: Judicial Council of California, Administrative Office of the Courts, Center for Families, Children and the Courts, 2002

55. Kerig PK. Children's coping with interparental conflict. In: Grych JH, Fincham FD, eds. Interparental conflict and child development: theory, research and applications. Cambridge University Press, 2001:213-45.

56. Dong M, Anda RF, Felitti VJ, et al. The interrelatedness of multiple forms of childhood abuse, neglect, and household dysfunction. Child Abuse Neglect 2004:28:771-84

57. Straus M, Hamby S, Boney-McCoy S, et al. The revised conflict tactics scales (CTS2): development and preliminary psychometric data. J Fam Issues 1996:17:283-316.

58. Reichenheim ME, Moraes CL. Comparison between the abuse assessment screen and the revised conflict tactics scales for measuring physical violence during pregnancy. J Epidemiol Commun Health 2004:58:523-7.

59. Clements CM, Oxtoby C, Ogle RL. Methodological issues in assessing psychological adjustment in child witnesses of intimate partner violence. Trauma Violence Abus 2008:9:114-27.

60. Greeno CG, Wing RR. Stress-induced eating. Psychol Bull 1994;115:444-64.

61. Steptoe A, Wardle J, Pollard TM, et al. Stress, social support and health-related behavior: a study of smoking, alcohol consumption and physical exercise. J Psychosom Res 1996; $\mathbf{4 1 : 1 7 1 - 8 0}$

62. Nemeroff CB. Neurobiological consequences of childhood trauma. J Clin Psych 2004;65(Suppl 1):18-28.

63. Wright R. Identification of domestic violence in the community pediatric setting need to protect mothers and children. Arch Pediatr Adolesc Med 2000;154:431-3. 